\title{
OS PRINCÍPIOS DE DARWIN NA CONSOLIDAÇÃO DOS CONTEÚDOS DE EVOLUÇÃO DO ENSINO MÉDIO
}

\section{THE PRINCIPLES OF DARWIN IN CONSOLIDATING THE CONTENTS OF EVOLUTION OF HIGH SCHOOL}

\author{
Bruna Malavazi Dell’ Antonio ${ }^{1}$, Vilacio Caldara Junior ${ }^{2}$ \\ ${ }^{1}$ Universidade Federal do Espírito Santo/ Mestranda pelo Programa de Pós-Graduação em Ciências \\ Biológicas (Biologia Animal), brunasda@hotmail.com \\ ${ }^{2}$ Instituto Federal de Educação, Ciência e Tecnologia do Espírito Santo - Campus Santa Teresa/Docente \\ do Curso de Licenciatura em Ciências Biológicas, vilacioj@ifes.edu.br
}

\section{RESUMO}

O conceito de Evolução Biológica, baseado na Seleção Natural, é considerado um guia articulador dos conteúdos da Biologia, além de contribuir para a construção do pensamento crítico dos alunos, devido ao seu caráter controverso. Entretanto, o seu ensino em sala de aula enfrenta obstáculos, como a falta de tempo, escassez de recursos didáticos e o conhecimento prévio dos alunos. Tendo em vista minimizar as dificuldades em se trabalhar o tema em sala de aula, objetivou-se nesse trabalho avaliar a eficácia da intervenção utilizando um protocolo de ensino de Evolução Biológica no Ensino Médio baseado nos cinco princípios fundamentais de Charles Darwin, por meio de instrumentos para o ensino. O projeto foi aplicado no Instituto Federal do Espírito Santo - Campus Santa Teresa, com duas turmas da terceira série do Ensino Médio. As informações dos jogos, site e vídeo serviram de base para trabalhar as premissas do protocolo e como fundamento para os conceitos do livro didático. Para a obtenção de dados, os alunos desenvolveram relatórios ao final de cada etapa, que foram analisados a partir do método pedagógico de categorização de conteúdos, quadros e gráfico. Verificou-se que o uso de uma metodologia alternativa mais dinâmica, estruturada nas premissas de Darwin, permitiu maior entendimento sobre a Evolução e despertou maior atenção dos discentes, colaborando para o desenvolvimento das aulas. Portanto, concluise que a proposta metodológica surge como uma alternativa eficaz quanto à articulação dos conceitos da Biologia à luz da Evolução, facilitando o trabalho do professor e potencializando a aprendizagem do aluno.

Palavras-chave: Teoria evolutiva, protocolo de ensino, metodologia alternativa.

\begin{abstract}
The concept of Biological Evolution, based in Natural Selection, is considered a guide to articulate the contents of Biology, besides contributing to the construction of scientific thinking, due to its controversial character. However, its teaching in classroom faces obstacles, like lack of time, shortage of didactic resources and the previous knowledge. In view of minimize the difficulties in working the theme in class, the objective of this study was to evaluate the effectiveness of the intervention using a teaching protocol of Biological Evolution in High School based on the five fundamental principles of Charles Darwin, through a dynamic approach with the teaching instruments. The project was applied at Federal Institute of Espírito Santo - Campus Santa Teresa, with two classes of the third grade of High School. The informations of the games, a website and video served as a basis for working the protocol premises and as a basis for the textbook concepts. To obtain data, the students developed reports at
\end{abstract}


the end of each stage, which were analyzed using the pedagogical method of categorization of contents, tables and graph. It was verified that the use of a more dynamic alternative methodology, structured in the premises of Darwin, allowed a greater understanding on the Evolution and awakened more attention of the students, collaborating for the development of the classes. Therefore, it is concluded that the methodological proposal appears as an effective alternative to articulating Biology concepts in the light of Evolution, facilitating the work of the teacher and enhancing student learning.

Key words: Evolution theory, teaching protocol, alternative methodology.

\section{INTRODUÇÃO}

O conceito de Evolução Biológica revolucionou o modo de pensar sobre o mundo, não só entre os cientistas da época, mas também em toda a sociedade moderna. Antes da metade do século XIX, o mundo era visto como algo constante que não havia sofrido modificações desde o dia da criação (MAYR, 2005; MOTA, 2013). Mas, como mencionado por Mota (2013), a teoria da Evolução baseada na Seleção Natural, proposta por Charles Darwin e Alfred Wallace, causou muitas indagações em relação às teorias criacionistas e evolucionistas da época.

Darwin, ao publicar o seu livro A Origem das Espécies, em 1859, causou ainda mais reboliço ao afirmar que a visão de muitos naturalistas, de que cada espécie foi criada de forma independente, era equivocada. Por isso, para Zimmermann (2013), tevese outro entendimento sobre a vida e, como dito por Mayr (2005), a constância do mundo foi refutada e a ciência notou a amplitude da evolução no mundo biológico e em uma série de novas ideologias.

Dessa forma, a Evolução, assim como outras temáticas da Biologia, pode despertar o pensamento crítico dos alunos, incitando-o a observar os temas trabalhados na disciplina e os acontecimentos sociais e políticos que o cercam de forma questionadora. Em vista da relevância da Evolução para as diversas áreas do conhecimento e, principalmente, para a Biologia, as Orientações Curriculares para o Ensino Médio (OCEM) (BRASIL, 2006, p. 22) determinaram que:

Um tema de importância central no ensino de Biologia é a origem e evolução da vida. Conceitos relativos a esse assunto são tão importantes que devem compor não apenas um bloco de conteúdos tratados em algumas aulas, mas constituir uma linha orientadora das discussões de todos os outros temas.

De acordo com Liporini e Periotto (2014), necessita-se promover a incorporação da Evolução para contribuir na assimilação de conteúdos como classificação dos seres 
vivos, interações ecológicas, genética de populações, fisiologia e morfologia comparadas e da especiação. Sendo assim, a Evolução é considerada um guia dentre as grandes áreas que constituem as Ciências Biológicas (LUCENA; GASPAR, 2007). Essa teoria, conforme Medeiros e Maia (2013), preocupa-se em explicar e estudar o surgimento e os mecanismos de mudanças presentes em toda a biodiversidade sem utilizar elementos sobrenaturais, o que justifica a sua magnitude dentro da Biologia. Contudo, esta não é trabalhada, muitas vezes, de forma plena em sala de aula (MOTA; LIRA-DA-SILVA, 2011).

As dificuldades em se trabalhar Evolução Biológica nas escolas estão relacionadas a uma formação docente insatisfatória, à falta de tempo, ao seu caráter abstrato e ao conhecimento prévio dos alunos, sendo este arraigado no senso comum e religioso. Os problemas atrelados à formação inicial do professor surgem da abordagem conceitual, metodológica e integradora (AMARAL; SILVA, 2013). Essas dificuldades foram justificadas por Silva, Silva e Teixeira (2011), afirmando que alguns cursos de Licenciatura em Ciências Biológicas dispõem de uma orientação insuficiente acerca do ensino de Evolução Biológica para seus alunos. Assim, os licenciandos enxergam o tema como um grande desafio a ser enfrentado durante as aulas no ensino básico. A escassez de recursos metodológicos aparece como mais um problema no ensino de Evolução, levando o docente a estabelecer o livro didático como único guia de suas aulas (GOEDERT et al., 2003). Além do material didático, Oleques et al. (2011) atribuíram as dificuldades ao tempo disponível e às crenças. Essa falta de tempo se refere ao currículo escolar, que propõe o ensino da teoria no final do ensino médio (TIDON; VIEIRA, 2009). O currículo não privilegia o caráter integrador da Evolução, refletindo na distribuição limitada do conteúdo no livro didático. Logo, apesar do reconhecimento da importância do conteúdo, este é marcado pela fragmentação nos livros (ZIMMERMANN, 2013).

A Evolução é pouco aceita entre a população geral como uma lei (MEDEIROS; MAIA, 2013; OLIVEIRA; BIZZO, 2011), ainda que apoiada pelas publicações científicas. A perspectiva deturpada da sociedade que incide na interpretação da Evolução se reflete nas escolas, onde, de acordo com Amorim e Leyser (2009), os alunos chegam carregados de um pluralismo de ideias, com uma bagagem cultural e noções de mundo divergentes. Os indivíduos, a partir das vivências, estão em constante construção do seu conhecimento. E os alunos não são diferentes. O conhecimento prévio destes influencia na percepção dos conteúdos, principalmente daqueles que 
despertam dúvidas e controvérsias. Diante disso, Santos e Calor (2007) argumentaram que os conceitos sobre a Teoria Evolutiva expostos pelos estudantes, suas crenças religiosas e visão de mundo biológico intervêm na aprendizagem desse assunto. Assim, compreensões equivocadas, internalizadas nos alunos por meio de mídias de massa e concepções religiosas, são uma barreira para o processo de ensino/aprendizagem da Evolução, além de omitirem o ensino formal científico (SANTOS; CALOR, 2007; LUCENA; GASPAR, 2007).

Diversos autores apontaram as crenças religiosas como fator que dificulta um eficiente processo de ensino/aprendizagem dos princípios da Evolução. Almeida (2012) demonstrou que a maioria dos alunos se baseia na escrita de Gênesis para explicar a origem do homem e das demais espécies. Assim, a compreensão da teoria evolutiva pelo indivíduo ganha forte intervenção das crenças religiosas (OLIVEIRA; BIZZO, 2011). Em consequência disso, Mota e Lira-da-Silva (2011) verificaram que boa parte dos alunos considera o homem como um ser perfeito e superior, acredita na inexistência da ancestralidade e descendência; e a Evolução é associada à melhoria e progresso.

Em vista disso, Araújo, Sousa e Sousa (2011) revelaram que o conhecimento prévio dos alunos, ligado às crenças e aos valores, impede uma compreensão total do tema. Bizzo (1991) verificou que os estudantes concebem a Teoria da Evolução como algo muito mais amplo do que a perspectiva científica biológica, associando o conceito a modificações em função do progresso do organismo. Amaral e Silva (2013) perceberam que os discentes visualizam a Evolução e a diversificação das espécies como algo intencional e não aleatório.

Como forma de minimizar essa problemática, Araújo, Sousa e Sousa (2011) reforçaram que os alunos, antes de assimilarem os conteúdos científicos, devem confrontar seu pensamento ideológico. Para tanto, o professor, na perspectiva de Amorim e Leyser (2009), deve assumir uma postura ética e metodológica frente ao conteúdo, propiciando a exteriorização das concepções alternativas, para que estas sejam esclarecidas à luz da ciência. Posto isto, o ensino de Evolução deve seguir o rigor científico ao ser trabalhado, sem que haja a deturpação e supressão de conceitos, principalmente daqueles considerados essenciais à apreensão do tema.

A percepção da Evolução é significativa, não só para explicar a diversidade biológica, mas também para promover reflexões críticas em seus atributos filosóficos e sociais por parte daqueles que a estudam (TIDON; VIEIRA, 2009; OLIVEIRA; BIZZO, 2011; AMARAL; SILVA, 2013; MOTA, 2013). Essa teoria, segundo Goedert et al. 
(2003), afetou todas as áreas do conhecimento, permitindo a avaliação das relações que mantemos com os outros seres vivos ao longo da história humana. Razera e Nardi (2006) afirmaram que formar alunos reflexivos sobre os valores existentes implicam em situações que estimulem a reflexão, as críticas e escolhas. Assim, o ensino de Biologia deve prezar pela Teoria da Evolução, pois é um tema estruturante e relevante para a construção do pensamento crítico do aluno. A sua abrangência sustenta os demais conteúdos da disciplina. No entanto, a abordagem do tema em sala de aula geralmente é inconsistente e demasiadamente curta. Os conceitos considerados essenciais para a compreensão da Evolução não são trabalhados rigorosamente, muitas vezes sendo perdidos em meio a equívocos conceituais dos professores.

Em vista dos aspectos apresentados, Tidon e Vieira (2009) reconheceram que o estudo de Biologia não pode ser comparado com o ato de memorizar palavras. Esses autores acreditam que a Evolução precisa ser assimilada como um extenso fundamento, apoiado nas premissas de Darwin, Wallace e outros evolucionistas notórios, fazendo com que o pensamento evolutivo seja compreendido integralmente. Então, o professor surge como o sujeito provocador da curiosidade dos discentes, apresentando a eles as evidências evolutivas com o uso de uma metodologia alternativa (AMARAL; SILVA, 2013). Assim, propõe-se que o ensino de Evolução Biológica esteja alicerçado nos cinco princípios estudados e publicados por Charles Darwin no livro A Origem das Espécies, em 1859: Origem única das espécies; Evolução por Seleção Natural, variação e adaptação; Relações de ancestralidade e descendência entre os organismos; Evolução lenta e gradual ou não; Existência de Seleção Sexual. Assim, objetivou-se neste trabalho avaliar a eficácia da intervenção utilizando um protocolo de ensino de Evolução Biológica do Ensino Médio baseado nos cinco princípios fundamentais de Charles Darwin, por meio de uma abordagem dinâmica com o uso de jogos, um site e vídeo.

\section{METODOLOGIA}

A intervenção foi desenvolvida no Instituto Federal de Educação, Ciência e Tecnologia do Espírito Santo (IFES) - Campus Santa Teresa, localizado na Rodovia ES-080, Km 93, no distrito de São João de Petrópolis, Santa Teresa (ES). Para tal, a

pesquisa foi apreciada pelo Comitê de Ética Científica. Sabendo que o conteúdo é abordado no último ano do Ensino Médio (TIDON; VIEIRA, 2009), determinou-se duas turmas da terceira série, totalizando um número de 52 participantes. Anteriormente ao 
desenvolvimento da metodologia, todos os discentes foram informados do objetivo das atividades, deixando-os cientes sobre a sua participação. Como forma de concordar com a intervenção, todos os alunos assinaram o Termo de Consentimento Livre e Esclarecido (TCLE).

Propôs-se abordar o conteúdo de Evolução Biológica do livro didático por meio de uma metodologia diferenciada, atrativa e interativa, de modo a facilitar o aprendizado dos discentes. Empregou-se, para isso, o método experimental sem grupo controle, com descrição das etapas. Assim, a estratégia pedagógica inovadora consistiu no uso de um protocolo de ensino com os cinco princípios fundamentais de Charles Darwin, já citados anteriormente, que foi trabalhado por meio de instrumentos para o ensino.

Utilizou-se para a intervenção dois jogos de tabuleiro extraídos da Revista Genética na Escola, o vídeo "Dance, monkeys, dance - Ernest Cline!!" e o site "Forebears". As informações dos instrumentos serviram como base para se trabalhar as premissas do protocolo e como fundamento para os conteúdos do livro didático usado na escola. Para que houvesse essa relação, durante a aula, com o auxílio de slides, explicou-se o assunto correspondente às informações que o instrumento utilizado abrangeu. Os exemplos e situações mais pertinentes, representados em cada instrumento, foram colocados nos slides, associando-os aos conceitos do conteúdo de Evolução. O intuito foi despertar o interesse dos discentes pela temática, promovendo a elucidação de suas dúvidas e a consolidação do tema de forma mais prática e lúdica.

A ordem de aplicação das atividades se baseou na organização dos conteúdos de Evolução do Ensino Médio, seguindo a sequência de complexidade dos mesmos. Primeiramente, os dois jogos foram trabalhados, sendo um por aula. Os alunos foram divididos em grupo e cada um recebeu o jogo. No decorrer da aula, verificou-se se os alunos estavam conseguindo desenvolver o jogo, esclarecendo eventuais dúvidas.

O primeiro foi o jogo "Entendendo a Seleção Natural". O jogo busca evidenciar que as populações de uma mesma espécie são submetidas a diferentes condições ambientais, possibilitando a atuação da Seleção Natural sobre as características herdáveis (genéticas) que diferenciam os indivíduos entre si. Então, por meio deste, pôde-se explicar a Seleção Natural, variação e adaptação, além do histórico e pensamento evolutivo.

Já o segundo instrumento foi o "Jogo da Evolução". Este tem como objetivo facilitar a identificação dos mecanismos evolutivos nas populações, promovendo a 
discussão e fortificação de conceitos como mutação, deriva genética, fluxo gênico e seleção natural. Sendo assim, foi possível discutir a Evolução lenta e gradual ou não; origem única das espécies; genética de populações e deriva genética. Como este jogo também aborda a atuação da seleção sexual sobre os fenótipos existentes nas populações, explicamos a Existência da Seleção Sexual para os discentes.

Por fim, para abordar o princípio das relações de ancestralidade e descendência entre os organismos, os alunos seguiram para o laboratório de informática da escola, onde puderam acessar o site "Forebears". A partir deste, eles pesquisaram o país de origem dos sobrenomes e descobriram a quantidade de pessoas com o seu sobrenome e os países que elas habitam. Logo, os discentes puderam perceber que o seu sobrenome surgiu em alguma localidade do mundo e que há uma relação de parentesco entre as pessoas. Em seguida, o vídeo "Dance, monkeys, dance!! - Ernest Cline" foi exibido através do Datashow. De acordo com o mesmo, os seres humanos são macacos, levantando a questão de que possuímos o mesmo ancestral comum mais recente, desmistificando a ideia do homem como ser superior. Ao final da aula, discutiu-se os conceitos e reflexões vistos através do site e vídeo, respectivamente, de modo a instigar a exteriorização do pensamento dos alunos e a reforçar os conceitos visualizados durante as aulas.

A obtenção dos dados teve um caráter qualitativo e foi feita a partir de relatórios entregues pelos alunos ao final de cada etapa. Os discentes foram instruídos a desenvolverem um relato em forma de texto, sendo permitida a colocação de opiniões sobre as dinâmicas e as explicações durante as aulas. Os discentes tomaram como base para o relato as seguintes questões: (1) quais eram suas principais dúvidas sobre a temática? Elas foram esclarecidas? (2) conseguiram assimilar novos conceitos? (3) Quais foram esses conceitos? (4) Os instrumentos foram positivos ou negativos para a aprendizagem das premissas da Evolução? E (5) houve maior entendimento de outros conceitos de Biologia, como Genética e Ecologia?

As análises das respostas foram qualitativas e quantitativas. Utilizou-se o método pedagógico de categorização de conteúdos, que consiste, basicamente, na sistematização das mensagens relacionadas ao contexto da pesquisa (CAVALCANTE; CALIXTO; PINHEIRO, 2014). Após a leitura dos relatórios, as respostas foram agrupadas em blocos, determinados segundo as cinco questões explicitadas acima, de modo a avaliar se a proposta é eficaz para a compreensão dos conceitos de Evolução Biológica. Em seguida, analisou-se as respostas em gráficos e tabelas. 


\section{RESULTADOS E DISCUSSÃO}

Após a leitura dos relatórios, verificou-se que o uso de uma metodologia alternativa mais dinâmica, estruturada nas premissas de Darwin, permitiu um maior entendimento dos conteúdos referentes à Evolução. Além disso, percebeu-se que os instrumentos chamaram mais a atenção dos alunos, colaborando para o desenvolvimento das aulas. Notou-se que a aplicação dos jogos despertou entusiasmo nos discentes, tanto é que eles reclamavam ao perderem e comemoravam ao ganharem vantagens. Essa mesma reação dos discentes foi mencionada por Knechtel e Brancalhão (2009), pois elas observaram que, com o jogo, os alunos se mostraram mais animados durante a aula. Desse modo, segundo as mesmas autoras, o professor consegue tornar a aula de Ciência/Biologia mais atrativa, abrangendo o conteúdo de forma contextualizada.

Além disso, pôde-se notar que a aplicação dos jogos anteriormente à explicação fez com que os alunos já tivessem uma visão sobre a temática. Isso permitiu uma melhor interação com eles, pois se conseguiu relacionar os conceitos de Evolução com as situações observadas nos jogos, favorecendo a aprendizagem dos alunos, ao estabelecer maior proximidade destes com o conhecimento científico (KNECHTEL; BRANCALHÃO, 2009). O site e o vídeo também causaram o mesmo efeito, surpreendendo os discentes, tornando a aula muito proveitosa e bem diferente do modelo expositivo. Desse modo, essa metodologia possibilitou maior facilidade na abordagem do conteúdo, além de uma melhor relação aluno-professor, em razão de aulas mais extrovertidas e atrativas.

Como mostrado no gráfico 1, dos 52 alunos participantes, 12 (34\%) disseram ter dúvidas quanto à Seleção Natural (quadro 1). Isso demonstra que, apesar desse processo ser muito importante para a compreensão da Evolução, possivelmente este não foi trabalhado durante o Ensino Básico ou, caso tenha sido visto, não foi dada a devida relevância em sua explicação. Sobre isso, Duarte, Araújo e Amaral (2014) puderam constatar que o ensino do evolucionismo desagregado e limitado apenas à última série do Ensino Médio provoca dúvidas e, até mesmo, erros conceituais nos alunos. Pode-se argumentar também que alguns professores, em virtude de uma formação deficiente quanto ao conteúdo evolucionista, podem apresentar conceitos incertos. Almeida e Chaves (2014) puderam constatar em sua pesquisa que $50 \%$ dos professores 
entrevistados encontram dificuldades ao trabalhar a Evolução, sendo a falta de domínio conceitual uma das justificativas.

\section{Gráfico 1: Principais dúvidas sobre a Evolução Biológica}

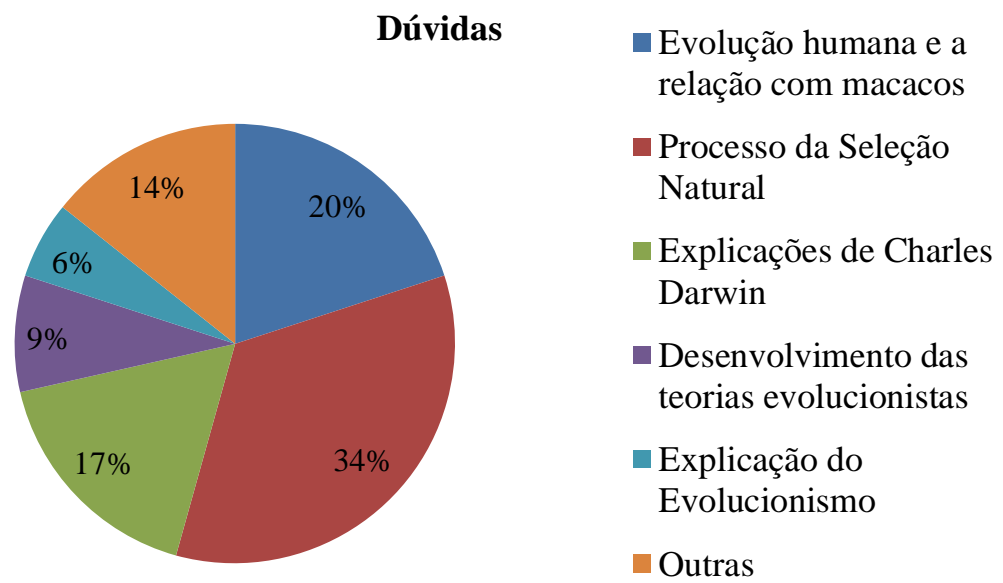

Fonte: Autor

Tomando como referência o princípio de Darwin "Seleção Natural, variação e adaptação", torna-se importante salientar que a apreensão do mecanismo da Seleção Natural depende do conhecimento acerca das mudanças genotípicas nas populações, podendo ou não gerar uma característica com alto valor adaptativo em relação às condições ambientais. Isto é, evidenciar a importância da variabilidade genética, que resulta em um leque de características diversas, no qual o ambiente atua seletivamente. Justifica-se o exposto com a argumentação de Sepulveda e El-Hani (2014, p. 253), pois, para eles, "um dos obstáculos à gênese do conceito darwinista de adaptação é a incompreensão de como um mecanismo variacional opera na mudança adaptativa de uma população".

Assim, a maior parte dos alunos não consegue absorver tais informações em razão do caráter abstrato do conteúdo. A partir disso, associado à influência do conhecimento prévio (SANTOS; CALOR, 2007) e com a carência de metodologias didáticas (GOEDERT et al., 2003), o aluno sente dificuldades em entender os conceitos.

Quadro 1: Relatos de alguns alunos sobre as dúvidas quanto ao processo da Seleção Natural.

\section{DÚVIDAS}


Aluno 1: "Eu tinha algumas dúvidas de como o ambiente selecionava, como se dava esse processo".

Aluno 2: “A principal dúvida que tive sobre o tema foi de como funcionava a seleção natural".

Aluno 3: "A questão de como o ambiente afetava a sobrevivência e a continuação das espécies através da seleção natural".

Aluno 4: "A minha principal dúvida era de como a teoria da Seleção natural se dava e como ela era comprovada cientificamente".

Aluno 5: "Haviam muitas dúvidas de seleção natural".

Fonte: alunos participantes da intervenção

Diante disso, promover um ensino que propicie o aluno a enxergar exemplos de uma forma mais prática pode fortalecer a aprendizagem. Sendo assim, Barreto et al. (2013) consideraram que os jogos podem auxiliar na complementação do processo de ensino/aprendizagem. Esta atividade lúdica mostrou situações que imitam as condições ambientais, o que aproximou os alunos de exemplos simples, facilitando a visualização da Evolução. Quanto a isso, uma aluna escreveu:

"Os instrumentos foram super positivos para a aprendizagem, pois cada carta mostrava na prática o que realmente acontece na evolução e seleção natural". (Aluno 5)

E os resultados obtidos evidenciaram que estes instrumentos, principalmente o primeiro jogo ("Entendendo a Seleção Natural"), contribuíram para um maior entendimento da Seleção Natural, já que a maioria dos alunos conseguiu conceituá-la, como demonstram os seguintes relatos dos mesmos alunos citados no Quadro 1:

"O primeiro jogo que realizamos foi importante pois creio que me ajudou a entender como funciona a seleção natural, e como uma população não adaptada ao ambiente pode ser dizimada aos poucos com o tempo". (Aluno 1)

"Ao longo das aulas vimos que o mecanismo é dependente doa ambiente que seleciona os seres vivos que estão melhor adaptados a ele e 'descarta' os menos adaptados". (Aluno 2) 
"Preservação das variações favoráveis e rejeição das variações prejudiciais". (Aluno 3)

"Mutações ao acaso que fizessem determinado ser se adaptar melhor ao meio o faria sobreviver e assim deixar mais descendentes que portariam a mesma modificação". (Aluno 4)

"A seleção natural seleciona os organismos mais adaptados deixando descendentes, já os menos adaptados são eliminados pelo ambiente”. (Aluno 5)

A segunda dúvida que mais apareceu nos relatórios, citada por sete alunos (20\%) (Gráfico 1), foi a respeito da evolução humana e a relação com os macacos (Quadro 2). A incompreensão deste assunto pode estar atrelada à perspectiva religiosa. Mota e Lirada-Silva (2011) notaram em seus resultados que boa parte dos alunos enxerga o homem como um ser sublime, celeste e como reflexo do Criador. Logo, surge uma barreira no processo de ensino/aprendizagem (SANTOS; CALOR, 2007; LUCENA; GASPAR, 2007), já que a Teoria da Evolução promove um pensar diferente sobre a existência do homem, contrastando com a ideia criacionista. Consequentemente, o aluno pode negar a explicação evolucionista, o que gera dúvidas.

Quadro 2: Relatos de alguns alunos sobre as dúvidas quanto à evolução humana e a relação com macacos.

\section{DÚVIDAS}

Aluno 6: "Antes da matéria ser estudada, particularmente tinha duvidas quanto a relação do ser humano e o macaco, como o ser humano evoluiu".

Aluno 7: "A minha duvidas são em relação do ser humano e o macaco, [...] como os pesquisadores acharam os fosseis eram parecido com o do corpo humano".

Aluno 8: "Uma coisa que intrigava a todos era essa correlação entre os macacos e os seres humanos".

Aluno 9: “As minhas principais dúvidas eram como o macaco e o ser humano poderiam descender de uma mesma espécie mas serem ao mesmo tempo tão diferentes".

Fonte: alunos participantes da intervenção 
Então a exibição do vídeo "Dance, Monkeys, dance - Ernest Cline!!” teve o intuito de provocar uma reflexão sobre essa questão, seguindo a argumentação de Araújo, Sousa e Sousa (2011), segundo a qual os alunos precisam questionar seus pensamentos ideológicos previamente à assimilação de conteúdos científicos. Abordouse, justamente, a ideia do "ser superior" que incide sobre o homem, pois, como constatado por Oliveira e Bizzo (2011), os aspectos ligados à origem e evolução do homem surgem como os mais rejeitados. Mas, deixou-se claro que as crenças não seriam recriminadas. O objetivo consistiu, apenas, em potencializar a compreensão da ancestralidade e descendência do homem e dos demais seres vivos, contando, também, com o auxílio do site "Forebears", retomando conceitos já vistos nas aulas anteriores.

Seis alunos (17\%) afirmaram ter dúvidas sobre as explicações de Darwin sobre a Evolução, enquanto três alunos (9\%) continham dúvidas sobre o desenvolvimento das teorias científicas que explicam a Evolução e apenas dois discentes $(6 \%)$ relataram que a explicação do Evolucionismo não estava esclarecida (Quadro 3). O pouco entendimento das explicações de Darwin é algo que compromete o aprendizado da teoria, pois se sabe que as conclusões de Darwin, associadas às de Alfred Wallace, indagaram as teorias evolucionistas e criacionistas que vigoravam na época (MOTA, 2013). E, após o reconhecimento da importância da explicação a partir da Seleção Natural, teve-se outro entendimento sobre a vida (ZIMMERMANN, 2013). Sobre o pensamento crítico, abordar as demais teorias (Fixismo e Lamarckismo) durante as aulas foi primordial para expor de forma clara que, dento do mundo científico, as teorias são refutáveis, desmistificando a ideia da verdade absoluta.

Sendo assim, a partir do jogo "Entendendo a Seleção Natural", o "Jogo da Evolução" e com o auxílio de slides, os alunos se deram conta da relevância das proposições de Darwin, tendo um entendimento potencializado, como descrito por um aluno:

"Tratando-se de um jogo de tabuleiro, a partir do qual entendemos os conceitos básicos da seleção natural, a atividade realizada é uma boa maneira de se estudar as proposições Darwinistas”. (Aluno 10)

Quadro 3: Relatos de alguns alunos sobre as dúvidas quanto às explicações de Darwin, ao desenvol vimento das teorias evolucionistas e à explicação do evolucionismo.

\section{DÚVIDAS}

\begin{tabular}{ll|}
\hline $\begin{array}{l}\text { Explicações de Charles } \\
\text { Darwin }\end{array}$ & $\begin{array}{l}\text { Aluno 11: "Eu tinha um pouco de dúvida nas ideias que Darwin } \\
\text { tinha". }\end{array}$ \\
\hline
\end{tabular}




\begin{tabular}{|ll|}
\hline $\begin{array}{l}\text { Aluno 12: "Minhas principais dúvidas consistia em não entender } \\
\text { muito bem a respeito da teoria das espécies de Darwin". }\end{array}$ \\
$\begin{array}{l}\text { Desenvolvimento das teorias } \\
\text { evolucionistas }\end{array}$ & $\begin{array}{l}\text { Aluno 13: "Minhas principais dúvidas estavam voltadas a parte de } \\
\text { como esses pesquisadores descobriram essas teorias, através de que, } \\
\text { como notaram e muito mais". }\end{array}$ \\
& $\begin{array}{l}\text { Aluno 14: “A minha principal duvida era entender as teorias de } \\
\text { Darwin e Lamarck, em saber distinguilas". }\end{array}$ \\
Explicação do & $\begin{array}{l}\text { Aluno 15: "Já sabia da Teoria da Evolução mas nunca tinha entrado a } \\
\text { dentro do assunto e queria saber exatamente como ocorreu esse } \\
\text { processo". }\end{array}$ \\
Aluno 16: "Algumas dúvidas em relação ao que era, como \\
funcionava e o por que desse acontecimento para a nossa \\
sobrevivência em determinados locais, o que isso proporcionava aos \\
seres e etc".
\end{tabular}

Fonte: alunos participantes da intervenção

Verificou-se que cinco alunos (14\%) apresentaram outras dúvidas (Quadro 4). Já outros 13 disseram que possuíam dúvidas, mas não as determinaram. Diferentemente, 2 alunos não apresentaram dúvidas, pois já haviam lido o capítulo do livro referente à Evolução, enquanto que outros 2 não mencionaram no texto se possuíam ou não questionamentos quanto à temática. Ao final da proposta, apenas um aluno permaneceu com dúvidas. Nota-se, então, que os instrumentos foram de enorme valia para o ensino e a aprendizagem dos conceitos evolutivos.

Quadro 4: Relatos dos alunos que tiveram outras dúvidas.

\section{DÚVIDAS}

Aluno 17: "A minha principal dúvida era de como ocorria a resistência de bactérias aos antibióticos".

Aluno 18: "Dúvidas a respeito dos tipos de seleção"

Aluno 19: "As dúvidas eram sempre o porque de uma característica se sobrepor a outra, já que todas eram essenciais para a sobrevivência e/ou procriação dos indivíduos".

Aluno 20: "Tinha dúvidas nas questões das vantagens e desvantagens das 
características de cada animal".

Aluno 21: "No estudo da evolução sempre obtemos duvidas, como: não identificar corretamente os fósseis ou sua importância, saber sobre as espécies ou sobre embriologia".

\section{Fonte: Alunos participantes da intervenção}

O entendimento de novos conceitos apareceu em todos os relatórios, destacandose o Darwinismo, Lamarckismo e Fixismo, além do conceito evolutivo e Seleção Natural (Tabela 1). Com este resultado, pode-se inferir que a organização dos conteúdos com base nos princípios de Darwin, aliada ao uso de instrumentos, possibilitou uma explicação mais objetiva, compreensiva e coerente, corroborando com a afirmação de Amaral e Silva (2013). Para tais autores, o ensino da Evolução precisa estar alicerçado nas evidências evolutivas e ser trabalhada por meio de metodologias alternativas. Tidon e Vieira (2009) estabeleceram, também, que o ensino de Evolução não pode ser visto como o ato de memorizar conteúdo.

Após a aplicação do "Jogo da Evolução", a maioria dos discentes conseguiu diferenciar os tipos de seleção, como no relato que se segue:

"A seleção artificial é feita pelo homem, exemplo: para a escolha de um touro bom para perpetuar a espécie, será escolhido o mais forte, bonito e que tenha um sêmen de boa qualidade genética. A seleção natural é feita pelo ambiente, é ele que escolhe o indivíduo que tenha força, inteligência, esperteza. Seleção sexual, esta é baseada no instinto de cada animal, porque tem alguns animais que brigam usando a força, o canto ou outra coisa para chamar atenção das fêmeas". (Aluno 22)

Tabela 1: Novos conceitos compreendidos pelos alunos após a intervenção.

\begin{tabular}{|l|l|}
\hline Conceitos & Número de alunos \\
\hline Darwinismo & 20 \\
\hline Lamarckismo & 17 \\
\hline Fixismo & 16 \\
\hline Conceito evolutivo & 8 \\
\hline Seleção Natural & 8 \\
\hline Variabilidade genética & 5 \\
\hline Deriva genética & 5 \\
\hline Mutação & 3 \\
\hline Seleção Sexual & 3 \\
\hline Especiação & 3 \\
\hline Efeito gargalo e efeito fundador & 1 \\
\hline
\end{tabular}

Fonte: Autor 
A relação das características dos animais em função da Seleção Natural e da Sexual foi outra questão que os alunos demonstraram ter compreendido. Destaca-se um relato:

"O animal que possuía um rabo azul e o outro que possuía o canto forte era melhor para se reproduzir, porém em relação a predação chamava mais atenção tornandoos uma presa fácil. Já os animais que tinham bico forte e camuflagem possuíam maior chance de sobrevivência em relação aos outros". (Aluno 23)

Percebe-se que os exemplos trabalhados no "Jogo da evolução" facilitaram a apreensão de conceitos fundamentais para o entendimento da Evolução segundo Darwin. Isso enfatiza a importância de metodologias inovadoras e dinâmicas, que aproximam o aluno de situações em que seja possível ter a maior noção de como esses conceitos, aparentemente tão abstratos e fora da realidade, têm, na verdade, uma notória dimensão na diversidade biológica.

Acerca dos jogos, site e vídeo, todos os alunos julgaram estes instrumentos de forma positiva, como demonstra este relato:

"O jogo foi uma boa escolha, [...], pois é uma forma que da para aprender-se assuntos tratados de forma extrovertida e fácil, principalmente fazendo com que nós alunos passe a ter um interesse maior pelo conteúdo. No segundo jogo, foi muito bom também para aprender o conteúdo, onde percebia-se que o pássaro que sofreu mutação, era favorecido pelos recursos naturais daquele meio ambiente, conseguiria se alimentar melhor gerando maior quantidade de filhotes, logo, formando superioridade em relação aos demais". (Aluno 24)

Nota-se que a utilização dos jogos foi significativa para a aprendizagem dos alunos. Essas atividades lúdicas trazem pontos positivos, pois permitem que os discentes vislumbrem o conteúdo com maior motivação e participação ao longo das aulas (AMORIM, 2013). Tomando os jogos como plano de fundo da intervenção, faz-se necessário enfatizar que a organização do conteúdo pautada no protocolo foi primordial para orientar a incorporação do lúdico com os conceitos de Evolução Biológica. Deste modo, os princípios de Darwin ordenaram a temática de maneira coerente com o raciocínio evolutivo, ressaltando os conceitos imprescindíveis para a compreensão da teoria. Então, aliado a isso, os jogos serviram como meio para despertar a curiosidade dos discentes, aproximando-os do conhecimento evolutivo, assim como para estabelecer a objetividade e facilidade para o trabalho docente.

Com relação à aula no Laboratório de Informática, na qual se trabalhou o site e o vídeo, os alunos afirmaram que esta foi diferente e interessante, como no relato abaixo: 
"O vídeo e o site foi uma forma diferente de aprendizado, boa. O vídeo foi bem dinâmico em sua explicação e o site foi mesmo um conhecimento que muitos não sabiam que poderiam ter e fazer uma análise junto aos conceitos que aprendemos". (Aluno 25)

Segundo os discentes, houve maior facilidade na visualização dos conceitos evolutivos, já que os slides, trabalhados após a aplicação dos jogos e contendo a matéria do livro didático, faziam referência às situações abordadas pelos instrumentos. Evidenciando tais vantagens, Jesus, Nere e Dias (2014) salientaram que as atividades lúdicas evocam a destreza dos alunos, levando-os a fazerem associações.

Infelizmente, por conta de um currículo engessado, resultando na falta de tempo (TIDON; VIEIRA, 2009), a metodologia utilizada pelo professor acaba sendo a tradicionalmente expositiva, o que pode não provocar o interesse dos alunos. Referente a essa carência de alternativas pedagógicas, um aluno mencionou:

"O aluno sempre reivindica por atividades diferentes e é muito bom quando essas atividades são realizadas afim de explicar algo da matéria e feita de maneira tão organizada tão adequada, como estas foram. Isso ajuda ainda mais na aprendizagem". (Aluno 26)

Então, para Jorge et al. (2014), os alunos, ao praticarem atividades lúdicas como o jogo, deixam de ser meros receptores de informações e passam a criticá-las de forma reflexiva, pois se sentem autônomos.

Além disso, o uso de jogos, ao requerer a formação de grupos, promove um momento de socialização e discussão entre os colegas quanto às questões ligadas ao conteúdo. Sobre a importância desses aspectos observados, um aluno declarou:

"O jogo, que nos foi passado, foi muito positivo pois mudou um pouco a rotina do aprendizado. Ele nos forneceu momento de lazer junto com aprendizado e interagimos em grupo a respeito do assunto, que de fato ajudou bastante". (Aluno 27)

Em vista destes benefícios em se aplicar jogos nas salas de aula, as Orientações Curriculares do Ensino Médio (BRASIL, 2006) determinaram que estas atividades proporcionam o desenvolvimento de atribuições para a comunicação, socialização, liderança e para o trabalho em grupo no âmbito formativo. 
No que concerne à última questão do relatório, todos os alunos conseguiram correlacionar a Evolução com Genética e Ecologia, melhorando a compreensão destes dois outros temas, como expôs um aluno:

"Portanto, a evolução também engloba conteúdos como a genética que seria mantida ou passada para as demais gerações e até o ambiente poderia interferir para a sobrevivência das espécies”. (Aluno 28)

Independentemente do uso de uma metodologia diferente da tradicional para o ensino da Teoria Evolutiva, percebe-se que o protocolo contendo os princípios de Charles Darwin, proposto como cerne da organização dos conteúdos, intensificou a clareza dos mesmos. Os alunos aceitaram muito bem a sua utilização, contribuindo para a aprendizagem da temática. Relacionada a isso, Tidon e Vieira (2009) mencionaram que o ensino de Biologia deve estar pautado nos fundamentos de Darwin, Wallace e outros evolucionistas influentes, estabelecendo uma abordagem enfática e integral da teoria. Zamberlan e Silva (2012) destacaram este caráter integrador, declarando que a Evolução Biológica é um guia abrangente de estruturação das explicações das várias áreas desta ciência. Confirmando o exposto, dois discentes escreveram:

"Boa maneira de estudar as proposições Darwinistas". (Aluno 16)

"Aprendemos de forma mais clara as premissas da Evolução". (Aluno 2)

Constata-se, portanto, que a Evolução é um tema articulador dentro da Biologia, pois os demais conhecimentos trabalhados dentro desta disciplina estão fundamentados nesta teoria. Por isso, o ensino de Biologia alicerçado na Evolução, que busque evidenciar a sua abrangência de forma clara, não omissa e de maneira coerente com os seus pressupostos, é essencial para a aprendizagem do aluno sobre esse componente curricular. De acordo com Liporini e Periotto (2014), para que haja melhor apreensão de conteúdos como a classificação dos seres vivos, genética de populações, interações ecológicas, fisiologia e morfologia comparadas e especiação, necessita-se incorporar a Evolução. As Orientações Curriculares para o Ensino Médio (BRASIL, 2006) reforçaram o argumento ao afirmarem que o tema Origem e Evolução da Vida assume enorme relevância ao associar os conteúdos trabalhados no ensino de Biologia. Além disso, esta temática incita debates, fomentando uma consciência mais questionadora nos discentes, pois como argumentado por Mota e Lira-da-Silva (2011), a teoria é provocadora de discussões, por apresentar um caráter controverso. 


\section{CONSIDERAÇÕES FINAIS}

Em vista dos relatos e da recepção dos alunos no decorrer das aulas, conclui-se que o uso dos princípios de Darwin como organizadores do conteúdo Origem e Evolução da Vida, trabalhados por meio de jogos, site e vídeo, potencializou a aprendizagem desta teoria. Apesar de ser comumente trabalhada ao final do Ensino Médio, podendo ser abordada de forma inadequada e não integradora (BIZZO; EL-HANI, 2009), verificou-se que a proposta metodológica surge como uma alternativa eficaz quanto à articulação dos conceitos da Biologia à luz da Evolução. Desta forma, o ensino se mostra menos complexo para o professor, uma vez que, segundo Goedert et al. (2003), as escolas carecem de material diferenciado confiável que complemente o livro didático.

Em relação ao aprendizado, os discentes puderam notar, de forma lúdica, quais os fatores e evidências da teoria, aproximando-os de exemplos fáceis e reais. Além disso, observou-se que a organização do conteúdo proposta contribuiu para a formação do raciocínio evolutivo, possibilitando uma perspectiva crítica e integradora sobre os demais conceitos. Assim, evidenciou-se como o processo evolutivo está presente na dinâmica do ambiente e na sobrevivência das espécies, de forma a enaltecer o vínculo com outros temas também ensinados na disciplina de Biologia, como Genética e Ecologia, aumentando a compreensão das premissas. Referente a isso, Carneiro e Rosa (2003) apoiaram ao colocarem que é preciso ensinar a Evolução Biológica associada a diversos conhecimentos.

Pode-se concluir, também, que os instrumentos, principalmente o vídeo e o site, incitaram o pensamento crítico nos alunos. Destaca-se o confronto com as visões antrópica e religiosa lançadas sobre a ancestralidade da espécie humana, que se configura como um dos obstáculos para uma aprendizagem efetiva da Evolução. Contudo, partindo de um ensino propiciador de discussões, os alunos, ao refletirem, puderam enxergar a explicação evolutiva a respeito das relações de ancestralidade e descendência entre as espécies.

Portanto, é preciso propor metodologias diferenciadas para se trabalhar conteúdos complexos e carregados de controvérsia, como a Evolução, para que o processo de ensino/aprendizagem ocorra de maneira mais fácil e interativa. Além disso, o uso de instrumentos para o ensino pode auxiliar o professor a agregar conceitos, antes trabalhados de maneira isolada e descontextualizada, promovendo uma melhor compreensão dos mesmos. 
Diante disso, percebe-se como a Teoria da Evolução assume uma ampla importância na organização da disciplina de Biologia ao permear todas as temáticas trabalhadas, além de estar presente, como descrito por Oliveira (2009), em outras áreas do conhecimento. Zamberlan e Silva (2012) fortificaram esta magnitude ao dizerem que o pensamento evolutivo é extremamente necessário para decifrar a Biologia, não sendo, portanto, um capítulo a parte, mas sim um eixo orientador para as explicações das diversas áreas desta ciência.

\section{REFERÊNCIAS}

ALMEIDA, D. F. Concepções de alunos do ensino médio sobre a origem das espécies. Ciência \& Educação, v. 18, n.1, p. 143-154, 2012.

ALMEIDA, E. R.; CHAVES, A. C. L. O ensino de Biologia Evolutiva: As dificuldades de abordagem sobre evolução no Ensino Médio em escolas públicas do estado de Rondônia. In: SIMPÓSIO NACIONAL DE ENSINO DE CIÊNCIA E TECNOLOGIA, 4., 2014. Ponta Grossa. Anais... Paraná, 2014. Disponível em: <http://sinect.com.br/anais2014/anais2014/artigos/ensino-debiologia/01408135602.pdf>. Acesso em: 29 de outubro de 2016.

AMARAL, J. A.; SILVA, M. E. S. Fatores que dificultam ou facilitam o ensinoaprendizagem de evolução biológica na visão de professores de Biologia em Mossoró/RN. In: CONGRESSO DE INICIAÇÃO CIENTÍFICA DO IFRN, 9., 2013. Currais Novos. Anais... Rio Grande do Norte, 2013. Disponível em:<http://www2.ifrn.edu.br/ocs/index.php/congic/ix/paper/view/1162>. Acesso em: 17 de abril de 2016.

AMORIM, A. S. A influência do uso de jogos e modelos didáticos no ensino de Biologia para alunos de Ensino Médio. 2013. 50f. Trabalho de Conclusão de Curso. Universidade Aberta do Brasil - UAB/UECE. Ceará, 2013.

AMORIM, M. C.; LEYSER, V. Ensino de Evolução Biológica: Implicações éticas da abordagem de conflitos de natureza religiosa em sala de aula. In: ENCONTRO NACIONAL DE PESQUISA EM EDUCAÇÃO EM CIÊNCIAS, 7., 2009.

Florianópolis. Anais... Belo Horizonte, MG. Ed: ABRAPEC, 2009. Disponível em: <http://posgrad.fae.ufmg.br/posgrad/viienpec/pdfs/1305.pdf>. Acesso em: $11 \mathrm{de}$ abril de 2016.

ARAÚJO, M. F. F.; SOUSA, R. A.; SOUSA, I. C. Instrumentação para o Ensino de Biologia I. Natal: EDUFRN, 2011.

BARRETO, L. M.; GAVA, M.; FERRARINI, T. D.; SANTOS, C. M.; FERREIRA, C. D.; CARMASSI, A. Jogo didático como auxílio para o ensino de Zoologia de Invertebrados. In: CONGRESSO INTERNACIONAL DE CIÊNCIAS BIOLÓGICAS, 1., 2013. Recife. Anais... Recife, PE, 2013. Disponível em:

<http://www.unicap.br/simcbio/wp-content/uploads/2014/09/JOGO- 
DID\%C3\%81TICO-COMO-AUX\%C3\%8DLIO-PARA-O-ENSINO-DE-ZOOLOGIADE-INVERTEBRADOS.pdf>. Acesso em: 29 de outubro de 2016.

BIZZO, N. EL-HANI, C. N. O arranjo curricular do ensino de evolução e as relações entre os trabalhos de Charles Darwin e Gregor Mendel. Filosofia e História da Biologia, v.4, p. 235-257, 2009.

BIZZO, N. M. V. Ensino de Evolução e História do Darwinismo. 1991. 494f. Tese (Doutorado em Educação) - Faculdade de Educação da Universidade de São Paulo, São Paulo.

BRASIL. Orientações Curriculares para o Ensino Médio, 2006. Disponível em: <http://portal.mec.gov.br/seb/arquivos/pdf/book_volume_02_internet.pdf >. Acesso em: 15 de maio de 2016.

CARNEIRO, A. P. N.; ROSA, V. L. "Três aspectos da Evolução" - Concepções sobre Evolução Biológica em textos produzidos por professores a partir de um artigo de Stephen Jay Gould. In: ENCONTRO NACIONAL DE PESQUISA EM EDUCAÇÃO EM CIÊNCIAS, 4., 2003. Bauru. Anais... Belo Horizonte, MG. Ed: ABRAPEC, 2003. Disponível em:

<http://fep.if.usp.br/ profis/arquivos/ivenpec/Arquivos/Orais/ORAL169.pdf>. Acesso em: 4 de fevereiro de 2016.

CAVAlCANTE, R. B.; CALIXTO, P.; PINHEIRO, M. M. K. Análise de Conteúdo: considerações gerais, relações com a pergunta de pesquisa, possibilidades e limitações do método. Informação e Sociedade: Estudos, v. 24, n.1, p. 13-18, jan./abr. 2014.

COIMBRA, R. L. A influência da crença religiosa no processo de ensino de Evolução Biológica. 2007. 75f. Dissertação (Mestrado em Ciências e Matemática) Universidade Luterana do Brasil, Canoas.

DUARTE, F. B. M. D.; ARAÚJO, M. F. F.; AMARAL, V. S. O ensino fragmentado da Evolução Biológica e concepções alternativas sobre este tema no ensino médio. Revista da SBEnBio, n. 7, 2014. Disponível em: <http://www.sbenbio.org.br/wordpress/wpcontent/uploads/2014/11/R0086-1.pdf>. Acesso em: 18 de abril de 2016.

GALVÃO, M. F.; BASTOS, R. W. MOREIRA,F. F.; RODRIGUES, A. C.; YOTOKO, K. S. C. Jogo da Evolução. Revista Genética na Escola, v. 7, n. 2, 2012.

GOEDERT, L.; DELIZOICOV, N. C.; ROSA, V. L. A formação de professores de Biologia e a prática docente - O ensino de Evolução. In: ENCONTRO NACIONAL DE PESQUISA EM EDUCAÇÃO EM CIÊNCIAS, 4., 2003. Bauru. Anais... Belo Horizonte, MG. Ed: ABRAPEC, 2003. Disponível em: <http://www.nutes.ufrj.br/abrapec/vienpec/CR2/p677.pdf>. Acesso em: 10 de abril de 2016.

JESUS, J.; NERES, J. N.; DIAS, V. B. Jogo didático: uma proposta lúdica para o ensino de Botânica no Ensino Médio. Revista SBEnBio, n. 7, 2014. 
JORGE, V. L.; GUEDES, A. G.; FONTOURA, M. T. S.; PEREIRA, R. M. M. Biologia limitada: um jogo interativo para alunos do terceiro ano do Ensino Médio. In: ENCONTRO NACIONAL DE PESQUISA EM EDUCAÇÃO EM CIÊNCIAS, 7., 2009. Florianópolis. Anais... Belo Horizonte, MG. Ed: ABRAPEC, 2009. Disponível em: <http://posgrad.fae.ufmg.br/posgrad/viienpec/pdfs/1580.pdf >. Acesso em: $14 \mathrm{de}$ novembro de 2016.

KNECHTEL, C.; BRANCALÃO, R. M. C. Estratégias lúdicas no ensino de Ciências. Secretaria de Estado da Educação - Superintendência da Educação, Diretoria de Políticas e Programas Educacionais - Programa de Desenvolvimento Educacional, Paraná, 2009.

LIPORINI, T. Q.; PERIOTTO, F. A Evolução Biológica na ótica de alunos do Ensino Médio. In: JORNADA DAS LICENCIATURAS DA USP, 5., 2014. São Carlos.

Anais... São Carlos, SP,2014. Disponível em: < http://vjornadalicenciaturas.icmc.usp.br/CD/EIXO\%205/59.pdf >. Acesso em: 8 de fevereiro de 2016.

LUCENA, D. P.; GASPAR, A. Ensino informal de Ciências e a aprendizagem da Evolução Biológica: um olhar vigotskiano. In: ENCONTRO NACIONAL DE PESQUISA EM EDUCAÇÃO EM CIÊNCIAS, 6., 2007. Florianópolis. Anais... Belo Horizonte, MG. Ed: ABRAPEC, 2007. Disponível em: < http://www.nutes.ufrj.br/abrapec/vienpec/CR2/p677.pdf>. Acesso em: 10 de abril de 2016.

MAYR, E. Biologia, ciência única: Reflexões sobre a autonomia de uma disciplina científica. São Paulo: Schwarcz, 2005.

MEDEIROS, T. A.; MAIA, E. D. A teoria da evolução: as dificuldades encontradas na relação ensino-aprendizagem. In: ENCONTRO NACIONAL DE PESQUISA EM EDUCAÇÃO EM CIÊNCOAS,9., 2013. Águas de Lindoia. Anais... Belo Horizonte, MG. Ed: ABRAPEC, 203. Disponível em: <http://www.nutes.ufrj.br/abrapec/ixenpec/atas/resumos/R1132-1.pdf >. Acesso em: 10 de abril de 2016.

MOTA, H. S. Evolução Biológica e Religião: Atitudes de Jovens Estudantes Brasileiros. 2013. 257f. Tese (Doutorado em Educação) - Faculdade de Educação da Universidade de São Paulo, São Paulo.

MOTA, P. S.; LIRA-DA-SILVA, R.M. Representações do Pensamento Evolutivo de Estudantes e Professores: Uso de Ferramentas Educativas de Projeto Darwin Now. In: ENCONTRO NACIONAL DE PESQUISA EM EDUCAÇÃO EM CIÊNIAS, 8., 2011. Campinas. Anais... Belo Horizonte, MG. Ed: ABAPEC, 2011. Disponível em: <http://www.nutes.ufrj.br/abrapec/viiienpec/resumos/R0273-3.pdf >. Acesso em: 7 de abril de 2016.

OLEQUES, L. C.; BOER, N.; TEMP, D. S.; BARTHOLOMEI-SANTOS, M. L. Evolução Biológica como eixo integrador no ensino de Biologia: Concepções e práticas de professores do Ensino Médio. In: ENCONTRO NACIONAL DE PESQUISA EM EDUCAÇÃO EM CIÊNCIAS, 8., 2011, Campinas. Anais... Belo horizonte, MG. Ed: 
ABRAPEC, 2011. Disponível em: < http://www.nutes.ufrj.br/abrapec/viiienpec/resumos/R1066-1.pdf>. Acesso em: 8 de dezembro de 2015.

OLEQUES, L. C.; NASCIMENTO, L.; BARTHOLOMEI-SANTOS, M. L.; TEMP, D. S. Entendendo a seleção natural. Revista Genética na Escola, v. 7, n. 2, 2012.

OLIVEIRA, G. S. Aceitação/rejeição da Evolução Biológica: atitudes de alunos da Educação Básica. 2009. 162f. Dissertação (Mestrado em Ciências e Matemática) faculdade de Educação da Universidade de São Paulo, São Paulo.

OLIVEIRA, G. S.; BIZZO, N. Aceitação da evolução biológica: atitudes de estudantes do ensino médio de duas regiões brasileiras. Revista Brasileira de Pesquisa em Educação em Ciências, v. 11, n. 1, 2011.

RAZERA, J. C. C.; NARDI, R. Ética no ensino de Ciências: Responsabilidades e compromissos com a evolução moral da criança nas discussões de assuntos controvertidos. Investigações em Ensino de Ciências, v. 11, n.1, p. 53-66, 2006.

SANTOS, C.M. D.; CALOR, A. R. Ensino de Biologia Evolutiva utilizando a estrutura conceitual da Sistemática Filogenética - II. Ciência \& Ensino, v. 2, n.1, 2007.

SEPULVEDA, C.; EL-HANI,C. N. Obstáculos epistemológicos e sementes conceituais para a aprendizagem sobre a adaptação: uma interpretação epistemológica e sociocultural dos desafios no ensino de evolução. Revista de Ensino de Ciências e Matemática, v. 16, n. 2, p. 237-263, 2014.

SILVA, M. G. B.; SILVA, R. M. L.; TEIXEIRA, P. M. M. A evolução biológica na formação de professores de Biologia. In: ENCONTRO NACIONAL DE PESQUISA EM EDUCAÇÃO EM CIÊNCIAS, 8., 2011. Campinas. Anais... Belo Horizonte, MG. Ed: ABRAPEC, 2011. Disponível em:

<http://www.nutes.ufrj.br/abrapec/viiienpec/resumos/R1457-1.pdf>. Acesso em: 10 abr. 2016.

TIDON, R.; VIEIRA, E. O ensino da evolução biológica: um desafio para o século XXI. ComCiência, n. 107, 2009.

ZAMBERLAN, E. S. J.; SILVA, M. R. O Ensino de Evolução Biológica e sua Abordagem em Livros Didáticos. Educação \& Realidade, v. 37, n. 1, p. 187-212, 2012. Disponível em: 〈http://www.ufrgs.br/edu_realidade〉. Acesso em: 10 de abril de 2016.

ZIMMERMANN, N. Para além da seleção natural: algumas considerações sobre as contribuições de 'Darwin como Geólogo' para o ensino de Biologia. Terrae, v. 9, 2-11, 2013. 